\title{
Role of Glutamatergic Projections from the Ventral CAI to Infralimbic Cortex in Context-Induced Reinstatement of Heroin Seeking
}

\author{
Na Wang',2, Feifei Ge',2, Cailian Cui*,', Yijing Li', Xiaowei Sun', Linlin Sun', Xinjuan Wang', Shuli Liu', \\ Haolin Zhang', Yan Liu', Meng Jia' and Mingda Yang' \\ 'Department of Neurobiology, School of Basic Medical Sciences, Key Laboratory for Neuroscience of the Ministry of Education and National Health \\ and Family Planning Commission, Neuroscience Research Institute, Peking University, Beijing, China
}

\begin{abstract}
The prelimbic cortex $(\mathrm{PL})$ and infralimbic cortex $(\mathrm{IL})$ play a role in context-induced reinstatement of heroin seeking in an animal model of drug relapse. Both the PL and IL receive direct glutamatergic projections from the ventral CAI (VCAI), which is also involved in contextinduced reinstatement of cocaine and heroin seeking. Here we studied the role of VCAI-PL and VCAI-IL projections in context-induced reinstatement of heroin seeking by using electrophysiological, neuropharmacological, chemogenetic, and molecular methods. We showed that context-induced reinstatement of heroin seeking caused selective activation of the VCAI-IL but not VCAI-PL glutamatergic projections, decreased synaptosomal GluA2 expression in the IL, impaired basal synaptic transmission, and facilitation of long-term depression (LTD) in the VCAI-IL pathway. Additionally, chemogenetic inactivation of the VCAI-IL but not vCAI-PL pathway decreased context-induced reinstatement of heroin seeking. Inactivation of the VCA I -IL pathway also reversed synaptosomal GluA2 downregulation and basal transmission reduction, and blocked LTD induction. Taken together, our results demonstrate a critical role of the VCAI-IL glutamatergic projection in context-induced reinstatement of heroin seeking in a rat model of drug relapse.

Neuropsychopharmacology (20 I8) 43, 1373-1384; doi:I0.1038/npp.2017.279; published online 20 December 2017
\end{abstract}

\section{INTRODUCTION}

Relapse to drug seeking is a fundamental challenge for drug users and over the last decades rates of relapse remained largely unchanged (Conklin and Tiffany, 2002; Khoo et al, 2017). Heroin-paired contexts, such as places of use and cousers, can trigger craving and relapse in addicts even after prolonged abstinence (Bouton, 1993; O'Brien et al, 1992; Wikler, 1973). Consistent with the clinical studies, reexposing rodents to a previous heroin-paired context reinstates extinguished drug seeking (Bossert et al, 2016, 2006, 2004, 2007, 2012). In this study, we implemented a rat model of context-induced heroin relapse, the ABA model. First, rodents are trained to self-administer heroin in a specific context (context A). Subsequently, heroin-reinforced responding is extinguished in a different (non-drug) context B. After extinction, rodents are re-exposed to context A or context B without heroin and tested for context-induced reinstatement testing (Crombag et al, 2008; Marchant et al, 2015).

\footnotetext{
*Correspondence: Professor C Cui, Department of Neurobiology, Neuroscience Research Institute, Peking University, 38 Xueyuan Road, Beijing 100191, China, Tel:/Fax: +86 108280 । 120,

E-mail: clcui@bimu.edu.cn

${ }^{2}$ These authors contributed equally to this work.

Received 28 April 2017; revised 31 October 2017; accepted 2 November 2017; accepted article preview online 14 November 2017
}

To date, several cortical and subcortical structures that play a role in context-induced reinstatement of drug seeking have been identified. Previous studies have shown that the ventral hippocampus plays a pivotal role in context-induced reinstatement of both cocaine (Lasseter et al, 2010) and heroin seeking (Bossert and Stern, 2014). Inactivation of ventral subiculum (vSub), the output region of ventral hippopampus, but not dentate gyrus, posterior CA1 or posterior dorsal hippocampus decreased context-induced reinstatement of drug seeking (Bossert and Stern, 2014; Fanselow and Dong, 2010; Lasseter et al, 2010). Selective inactivation of the excitatory projections from the vSub to nucleus accumbens (NAc) shell decreased context-induced reinstatement of heroin seeking (Bossert et al, 2016). Two mPFC sub-regions, the PL and the IL (Riga et al, 2014), receive direct ipsilateral projections from the vCA1, which is involved in emotion-related and contextual memory processing (Fanselow and Dong, 2010; Jay et al, 1996). However, the role of these projections in context-induced reinstatement is unknown.

Drug addiction is thought to share molecular mechanisms that are also engaged in memory learning and memory (Hyman and Malenka, 2001). AMPA receptor (AMPAR) trafficking induces long-lasting changes in the strength of synapses, and these alterations are thought to serve as cellular substrates of learning and memory (Yu et al, 2013). GluA2, a subunit of AMPARs, regulates some of the key 
properties of AMPARs, including $\mathrm{Ca}^{2+}$ permeability, channel conductance, receptor trafficking, and basal synaptic strength (Asrar and Jia, 2013). It has been reported that downregulation of synaptic GluA2 is linked to the expression of long-term depression (LTD) (Connor and Wang, 2016). Blockade of GluA2 endocytosis with the Tat-GluA2 3 Y interference peptide (Dalton et al, 2008) impaired amphetamine-induced behavioral sensitization (Choi et al, 2014), extinction of morphine-induced conditioned place preference (Dias et al, 2012), and reinstatement of heroin seeking triggered by a drug-associated cue (Van den Oever et al, 2008). Based on these reports, we hypothesized that the alterations in GluA2 levels and GluA2-implicated synaptic plasticity might contribute to context-induced reinstatement of heroin seeking.

We have used the ABA renewal context-induced reinstatement procedure to investigate whether the vCA1-PL and vCA1-IL pathways play a role in context-induced reinstatement of heroin seeking in rats. We also studied the role of molecular changes in synaptic plasticity that may occur in these pathways that play a role in context-induced reinstatement.

\section{MATERIALS AND METHODS}

\section{Animals}

Male Sprague-Dawley rats were individually housed in a temperature- and humidity-controlled environment with a reversed 12:12 h light-dark cycle. All experimental procedures were approved by the Animal Use Committee of the Peking University Health Science Center.

\section{Heroin SA, Extinction, and Reinstatement Testing}

Heroin (diacetylmorphine $\mathrm{HCl}$; Academy of Military Medical Science) was dissolved in sterile saline and infused at a volume of $65 \mu$ l over $2.3 \mathrm{~s}$ at a dose of 0.1 (first six sessions of heroin self-administration) and 0.05 (last six sessions of heroin self-administration) $\mathrm{mg} / \mathrm{kg} /$ injection (Bossert et al, 2006). Rats were trained to self-administer heroin during the dark cycle for 3-h per day for 12 days in context A. Nosepokes in one hole activated the heroin infusion pump paired with a tone-light cue for $5 \mathrm{~s}$ (active nose-poke). Nose-pokes in the other hole were also recorded but rats receive neither cue presentation nor heroin infusion (inactive nose-poke). A fixed-ratio of one (FR 1) reinforcement schedule was used, with a 20-s timeout period after each infusion. For the next 14 days, rats received extinction training in a different context-context B for 3-h per day. During this phase, nosepokes in previous active hole led to only presentation of the tone-light cue for $1 \mathrm{~s}$ but not heroin. During reinstatement testing, the rats were re-exposed to context $\mathrm{A}$ (ABA group) or context $\mathrm{B}$ (ABB group) without heroin infusions. Reinstatement testing lasted for 30,60 , 90, or $120 \mathrm{~min}$, depending on the subsequent biochemical analysis.

\section{Procedures}

Experiment 1: re-exposing rats to a heroin-paired context selectively activates the vCA1-IL glutamatergic projections. Retrograde fluorogold tracer (FG, a retrograde tracer, $4 \%$,
$0.3 \mu \mathrm{l}$ (Myers et al, 2014)) was microinjected unilaterally into the PL (AP, $+3.0 \mathrm{~mm}$; ML, $\pm 0.6 \mathrm{~mm}$; DV, $-3.0 \mathrm{~mm})(n=4$ per group) or IL (AP, $+3.0 \mathrm{~mm}$; $\mathrm{ML}, \pm 0.6 \mathrm{~mm}$; $\mathrm{DV}$, $-4.4 \mathrm{~mm}$ ) ( $n=4$ per group) between the SA training and extinction phases. During reinstatement testing, the ABA group and $\mathrm{ABB}$ group were re-exposed to context $\mathrm{A}$ and $\mathrm{B}$ respectively for $90 \mathrm{~min}$. At the end of the test session, rats were anesthetized and perfused transcardially with $200 \mathrm{ml}$ of $0.9 \%$ saline followed by $350 \mathrm{ml}$ of $4 \%$ paraformaldehyde (PFA) in $0.1 \mathrm{M}$ phosphate-buffered saline ( $\mathrm{pH} 7.4$ ) (Liu et al, 2014). Whole brains were collected for subsequent immunohistochemical analyses (Supplementary Materials and Methods).

Experiment 2: protein levels of synaptosomal GluA2 and pY876 GluA2 in the IL after re-exposure to a heroin-paired context. After re-exposure to context A or B for $30 \mathrm{~min}$, the rats were decapitated immediately and the brains were quickly retrieved and homogenized. Total and synaptosomal protein fractions of GluA1, GluA2 and phosphorylation levels of GluA2 were determined in the PL ( $n=6$ per group) and IL ( $n=6$ per group) by western blot (Supplementary Materials and Methods).

Experiment 3: basal synaptic transmission and LTD induction in the vCA1-IL pathway after re-exposure to a heroin-paired context. After re-exposing rats to context $\mathrm{A}$ ( $n=4$ per group) or B ( $n=4$ per group) for $60 \mathrm{~min}$, synaptic plasticity alterations in the vCA1-IL pathway were investigated using in vivo electrophysiology (Supplementary Materials and Methods) in anesthetized rats. The procedures for electrode implantation, recording evoked field potentials (FPs) and LTD induction were described previously (Takita et al, 1999). We calculated the mean FPs amplitude at baseline $(30 \mathrm{~min})$ and the amplitude after low frequency burst stimulation $(60 \mathrm{~min})$.

Experiment 4: effect of pharmacological disconnection of the vCA1-IL pathway on context-induced reinstatement of heroin seeking. We divided rats into five groups $(n=6-9$ per group). The control group was injected with saline into the unilateral vCA1 (AP, $-5.8 \mathrm{~mm}$; $\mathrm{ML}, \pm 5.4 \mathrm{~mm}$; DV, $-7.0 \mathrm{~mm}$ ) and ipsilateral or contralateral IL (AP, $+3.0 \mathrm{~mm}$; $\mathrm{ML}, \pm 0.6 \mathrm{~mm}$; DV, $-4.4 \mathrm{~mm})$. The ipsilateral or contralateral group was microinjected with a mixture of baclofen + muscimol $\left(\mathrm{B}+\mathrm{M}, \mathrm{GABA}_{\mathrm{B}}\right.$ and $\mathrm{GABA}_{\mathrm{A}}$ receptor agonists, $125 \mathrm{ng}$ of each drug/ $\mu \mathrm{l}, 0.3 \mu \mathrm{l} /$ side; Sigma (St Onge and Floresco, 2010)) into the unilateral vCA1 5-10 min before reinstatement testing, and Tat-GluA $2_{3 \mathrm{Y}}((-3 \mathrm{Y}$ group) or its control peptide Tat-GluA2 $3 \mathrm{~A}$ ( $-3 \mathrm{~A}$ group), $15 \mathrm{pmol} / 0.3 \mu \mathrm{l} /$ side, ANA SPEC; (Mao et al, 2013)) was injected into the ipsilateral or contralateral IL $1 \mathrm{~h}$ before reinstatement testing. Microinfusions were made with a syringe pump at a rate of $0.1 \mu \mathrm{l} / \mathrm{min}$ connected to $5 \mu \mathrm{l}$ Hamilton syringes attached via polyethylene tubing to injectors (outer diameter, $0.41 \mathrm{~mm}$; inner diameter, $0.25 \mathrm{~mm}$; RWD Life Science Co., Ltd). The injectors were left in place for an additional $2 \mathrm{~min}$ to allow for drug diffusion. At the end of the behavioral tests, cannula placements were estimated by Nissl staining using light microscopy. Seventy-two hours after reinstatement testing, 
a
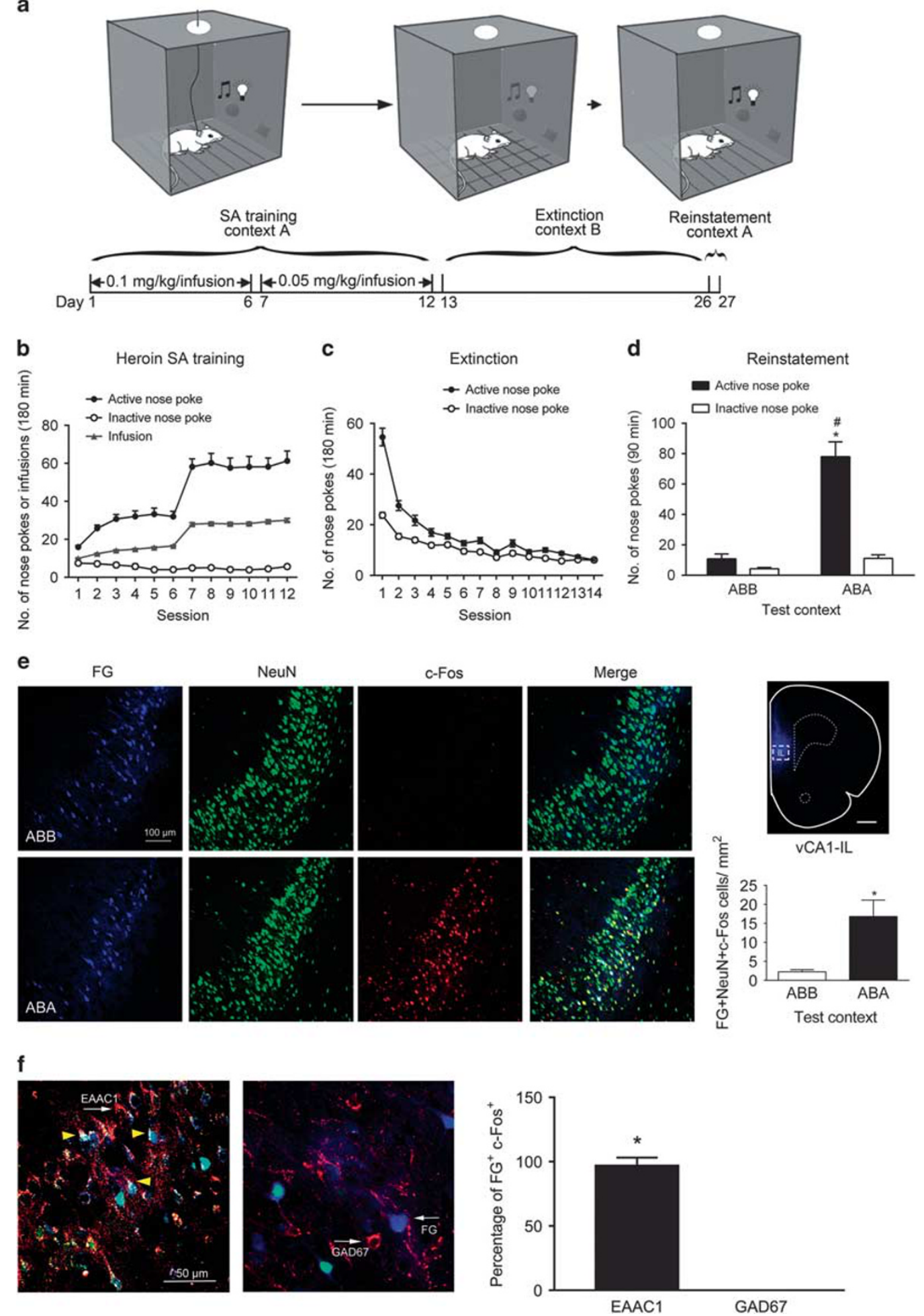

Figure I Re-exposure to a heroin-paired context activated the VCAI-IL glutamatergic projections. (a) Schematic showing the ABA procedure of contextinduced reinstatement of heroin seeking. (b) Number of active, inactive nose-pokes and heroin infusions were recorded daily during heroin SA training in context A. (c) Number of active and inactive nose-pokes was recorded daily during daily extinction training in context B. (d) Number of active and inactive nose-pokes exposure to context $A(A B A)$ or context $B(A B B)$ during reinstatement testing. Two-way ANOVA, $* P<0.05$ vs inactive nose-pokes, ${ }^{\#} P<0.05$ vs ABB group, $n=8$ per group. (e) Left, representative images of FG (injected in IL, blue), NeuN (green) and c-Fos (red) labeling in the vCAI after re-exposure rats to context A or context B. Scale bar, $100 \mathrm{\mu m}$. Top right, representative photomicrograph of FG injection site of the IL. Scale bar, I mm. Bottom right, number of FG, NeuN, and c-Fos triple-labeled (FG + NeuN + c-Fos) neurons per $\mathrm{mm}^{2}$ in the vCAI. *P $<0.05$ vs the ABB group using an unpaired $t$-test, $n=4$ per group. (f) Representative images of FG (blue), c-Fos (green), and EAACI (red) or GAD67 (red) in the vCAI of the ABA group. White arrows showing the neurons expressing EAACI (left) GAD67 and FG (right), yellow triangles showing the neurons expressing FG, c-Fos, and EAACAI. Scale bar, $50 \mu \mathrm{m} . * P<0.05$ vs GAD67 using an unpaired t-test. $n=4$ per group. Data are depicted as the mean \pm SEM. 
the rats were trained for saccharin SA and tested for locomotor activities.

Experiment 5a: effect of chemogenetic silencing of the vCA1-IL pathway on context-induced reinstatement of heroin seeking. Two weeks before heroin SA training, rats were microinjected with a virus (AAV8-hSyn-hM4D(Gi)mCherry or AAV5-hSyn-mCherry; $1 \mu$ l per side; $1 \times 10^{12}$ particles/ml; Vector Core at the University of North Carolina) (Mahler et al, 2014) bilaterally into the vCA1. Clozapine- $N$-oxide (CNO, $1 \mathrm{mM}, 0.3 \mu$ l per side; Tocris) or saline was administered bilaterally into the IL $(n=7$ per group) or PL ( $n=6-7$ per group) of the virus-infected rats 5 min before reinstatement testing. Seventy-two hours after reinstatement testing, rats were trained for saccharin SA. Cannula placements and $\mathrm{hM} 4 \mathrm{D}(\mathrm{Gi})$ receptor expression were examined using immunohistochemical analyses.

Experiment 5b: effect of chemogenetic inactivation of the $v C A 1-I L$ pathway on glutamatergic alterations induced by re-exposure to a heroin-paired context. The rats were killed and their brains were collected immediately after the 30-min reinstatement testing for western blot. Synaptosomal protein fractions of GluA2 and phosphorylation of GluA2 at Y876 was examined in the IL after context-induced reinstatement testing.

Rats were prepared for in vivo electrophysiology after reinstatement testing. $\mathrm{CNO}$ or saline was microinjected into the IL of the virus-injected rats (mCherry or hM4D(Gi)) $30 \mathrm{~min}$ before LTD induction. A microinjector (outer diameter, $0.41 \mathrm{~mm}$; inner diameter, $0.25 \mathrm{~mm}$; RWD Life Science Co., Ltd) was slowly $(10 \mu \mathrm{m} / 30 \mathrm{~s})$ inserted into the IL ( $200 \mu \mathrm{m}$ rostral to the tip of the recording electrodes). After FPs were stable for at least $15 \mathrm{~min}$, the drug (CNO or saline, $0.3 \mu \mathrm{l}, 0.1 \mu \mathrm{l} / \mathrm{min}$ ) was infused through a syringe pump connected to a Hamilton syringe. Then, baseline FPs were recorded for $30 \mathrm{~min}$ before LTD induction.

\section{Statistical Analysis}

Graph Pad Prism (Version 6, GraphPad) was used to statistically analyze the data sets and create graphs. Data are presented as the mean \pm standard error of the mean (SEM), and statistical significance was set at $P<0.05$. The results of immunohistochemical data, western blot analysis and LTDinduced changes in FPs, inactivation of the vCA1-IL projections in the saccharin SA and locomotor activity were analyzed using two-tailed unpaired $t$-tests. Two-way ANOVAs followed by Sidak's multiple comparisons tests were used to analyze other data. Additionally, the results of post hoc analyses by asterisks are shown in the figures but they are not described in the Results sections.

For more information in detail, please refer to the Supplementary Materials and Methods.

\section{RESULTS}

Experiment 1: Re-exposure to a Heroin-paired Context Activated the vCA1-IL Glutamatergic Projections

As shown in Figure 1, rats showed stable heroin self-intake and stable responses at the active and inactive nose-poke holes during the 12-day training phase in context A. When the dose of heroin was decreased from 0.1 to $0.05 \mathrm{mg} / \mathrm{kg} /$ infusion, the rats showed a reliable increase in active nosepoke responding and thus heroin infusion rates (Figure 1b). Then, rats underwent extinction training in a different environment-context $\mathrm{B}$-and discontinued heroin intake for 14 days. The number of active and inactive nose-pokes significantly decreased over extinction training from $53.7 \pm 3.0$ in the first session to $6.6 \pm 0.5$ nose-pokes in the last session (Figure 1c). Rats were then randomly assigned into context $\mathrm{A}(\mathrm{ABA})$ or context $\mathrm{B}(\mathrm{ABB})$ for re-exposure on test day. Rats exposed to context $A$ had a significantly higher number of active nose-pokes than those exposed to context B. The statistical analysis showed a significant interaction between group and number of nose-poke $\left(F_{(1,28)}=32.05\right.$, $P<0.0001$; Figure 1d).

Retrograde tracer FG was injected into the IL to trace the vCA1-projected neurons. Injection sites were verified in Figure 1e, top right. FG-positive neurons were readily visible in vCA1 from the IL (Figure 1e, first panel). Comparable number of FG-positive neurons was detected in vCA1 from the $\mathrm{ABA}$ and $\mathrm{ABB}$ groups $(242.027 \pm 25.933 v s$ $234.998 \pm 6.175$ per $\mathrm{mm}^{2}, \mathrm{t}_{6}=0.264, P=0.801$; Figure $1 \mathrm{e}$ ). To assess whether context-induced reinstatement of heroin seeking activates the vCA1-IL projection neurons, triplelabeling was performed in vCA1 slice-FG, NeuN (a marker of mature neurons), and c-Fos (a neuronal activation marker). The number of FG, NeuN, and c-Fos triplepositive cells in the ABA group was significantly higher than that in the $\mathrm{ABB}$ group $(16.797 \pm 4.317$ vs $2.240 \pm 0.571$ per $\mathrm{mm}^{2} ; \mathrm{t}_{6}=3.34, P=0.0156$; Figure $\left.1 \mathrm{e}\right)$. FG tracing and triple labeling was also performed in vCA1-PL pathway (Supplementary Figure S1). FG-positive projection neurons were also identified in vCA1, though to a less extent $\left(61.833 \pm 5.904\right.$ vs $52.296 \pm 4.212$ per $\mathrm{mm}^{2}$, ABA vs $\mathrm{ABB}$; $\left.\mathrm{t}_{6}=1.315, P=0.236\right)$. In contrast with vCA1-IL pathway, the $\mathrm{ABA}$ and $\mathrm{ABB}$ groups displayed similarly low number of triple-positive cells in vCA1 $(2.660 \pm 0.652$ vs $1.540 \pm 0.242$ per $\mathrm{mm}^{2}$, ABA vs $\mathrm{ABB} ; \mathrm{t}_{6}=1.611, P=0.158$; Supplementary Figure S1). To identify the property of these activated vCA1IL projection neurons during heroin relapse, we used glutamatergic marker EAAC1 to further identified that the activated IL-projecting (FG + c-Fos) cells in the vCA1 were co-localized with EAAC1, but not GAD67 (marker of GABAergic neurons (Kadriu et al, 2012)) (Figure 1f). The percentage of $\mathrm{FG}^{+} \mathrm{Fos}^{+} \mathrm{EAACl}^{+}$was $96.88 \% \pm 3.13 \%$, while the percentage of $\mathrm{FG}^{+} \mathrm{Fos}^{+} \mathrm{GAD}^{+}$was 0 . These results indicate that the vCA1-IL projections activated by the heroin-paired context are glutamatergic.

\section{Experiment 2: Re-exposing rats to a Heroin-paired Context Decreased in Synaptosomal GluA2 and Increased pY876 GluA2 in the IL}

Downregulation of GluA2 on synaptic membranes has been associated with cue-induced relapse to heroin-seeking (Van den Oever et al, 2008). Therefore, we examined the total and synaptosomal protein of GluA1 and GluA2 (the main subunits of AMPARs) in the IL after the 30-min reinstatement testing. The reduction of synaptosomal GluA2 protein was significantly higher in ABA (50.9\%) than that in the ABB group $\left(t_{10}=3.00, P=0.0132\right)$, though synaptosomal 
a

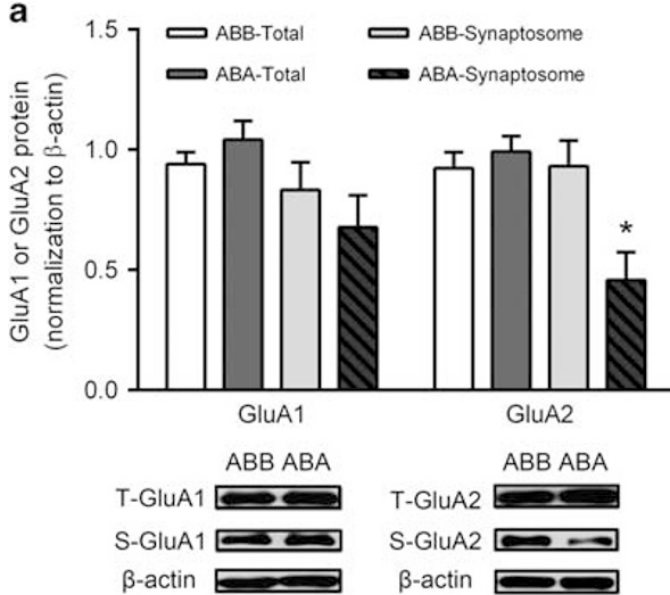

b

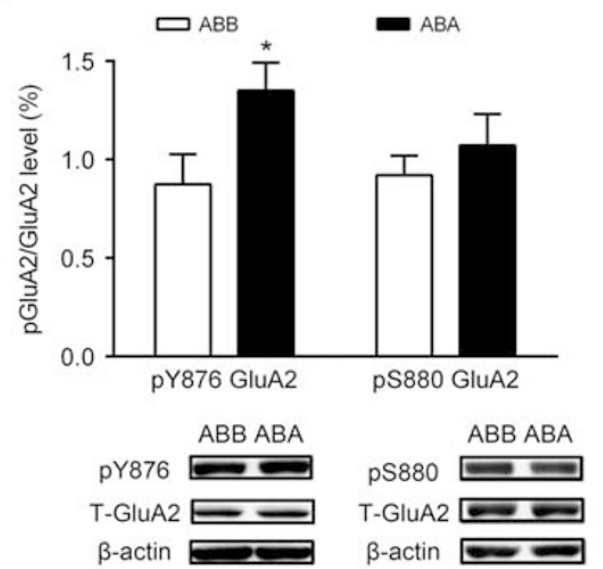

c
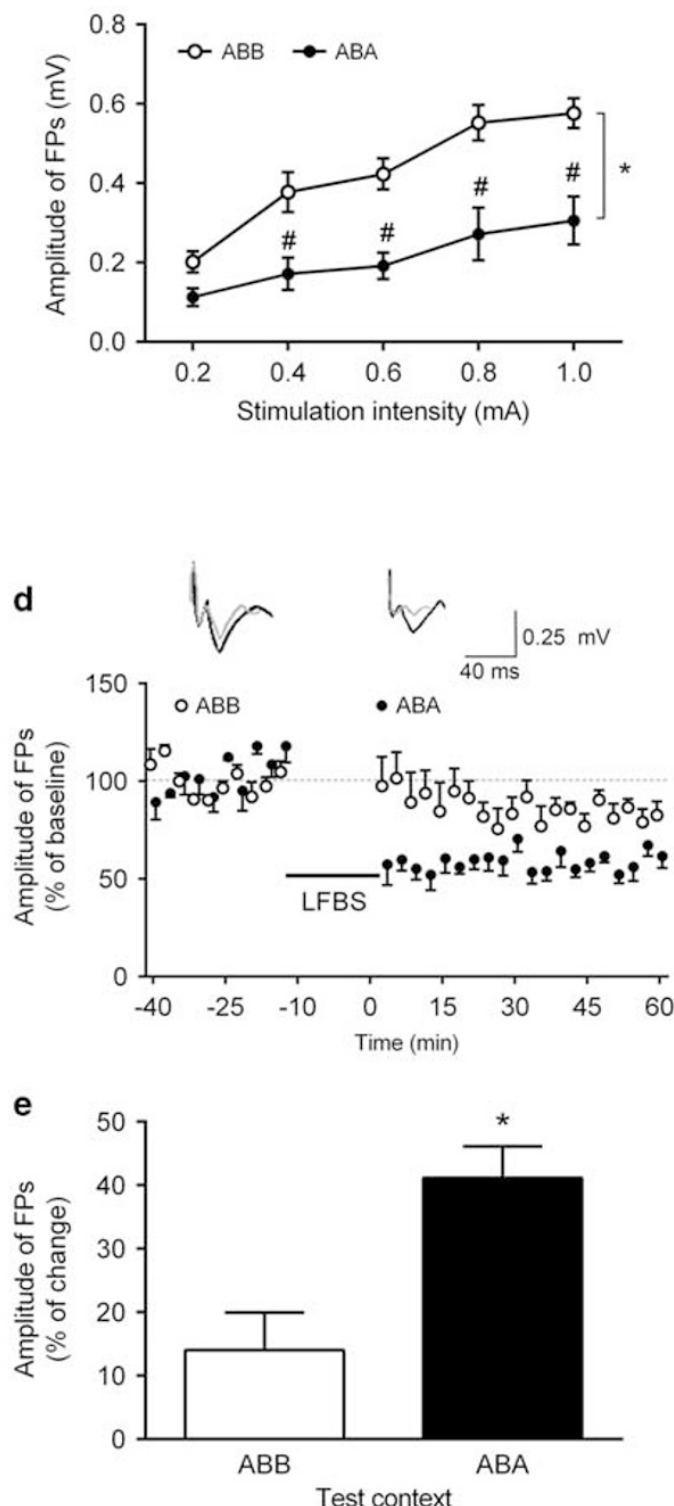

Figure 2 Re-exposure to heroin-paired context decreased synaptosomal GluA2, increased pY876 GluA2 in the IL, impaired basal synaptic transmission, and facilitated LTD induction in the VCAI-IL pathway. (a) Total and synaptosomal protein levels of GluAI and GluA2 in IL after context-induced reinstatement of heroin seeking. ${ }^{*} P<0.05$ vs the ABB group using unpaired $t$-test, $n=6$ per group. (b) Ratio of pY876 GluA2/GluA2 and pS880 GluA2/GluA2 protein levels in the IL after context-induced reinstatement of heroin seeking. $* P<0.05$ vs the ABB group using unpaired $t$-test, $n=6-7$ per group. (c) Input-output curves. Two-way ANOVA, ${ }^{*} P<0.05$, vs the ABB group; ${ }^{*} P<0.05$ vs each stimulation intensity, $n=4$ per group. (d) LTD induction in the vCAI-IL pathway after LFBS stimulation after exposure to the heroin-paired context, $n=4$ per group. Representative traces at the baseline and after LFBS stimulation are shown. Calibration: vertical scale bar, $0.25 \mathrm{mV}$; horizontal scale bar, $40 \mathrm{~ms}$. (e) Summary of the magnitude change of LFBS-induced LTD in each group. Amplitude of FPs after the LFBS stimulation represented as a percent change from the baseline. ${ }^{*} P<0.05$, vs the ABB group using unpaired $t$-test, $n=4$ per group. Data are depicted as the mean \pm SEM.

GluA1 $\left(\mathrm{t}_{10}=0.890, \quad P=0.400\right)$, total GluA1 $\left(\mathrm{t}_{10}=1.11\right.$, $P=0.294)$, or GluA2 $\left(\mathrm{t}_{10}=0.743, P=0.475\right)$ protein remained unaffected (Figure 2a). Context-induced heroin seeking did not affect the total or synaptosomal AMPARs expression in the PL (Supplementary Figure S2a).

Post-translational modifications regulate protein dynamics (Beltrao et al, 2013). Thus we measured the phosphorylation of the GluA2 at Y876 and S880, which has been shown to promote the internalization of GluA2 (Hayashi and Huganir, 2004; Seidenman et al, 2003), in the IL and PL after the reinstatement testing. Results showed that the ratio of pY876 GluA2/ total GluA2, but not pS880 GluA2/ total GluA2, was significantly increased in the IL in the ABA group (54.3\%) compared with the ABB group $\left(t_{11}=2.29, P=0.043\right)$ (Figure 2b), whereas the ratio of pY876 GluA2/ total GluA2 $\left(\mathrm{t}_{11}=0.465, \quad P=0.651\right)$ and $\mathrm{pS} 880$ GluA2/ total GluA2 $\left(\mathrm{t}_{11}=0.325, \quad P=0.751\right) \quad$ in the PL was unaffected (Supplementary Figure S2b). These results indicate that context-induced reinstatement of heroin seeking decreased synaptosomal GluA2 protein level with an increase in 
a
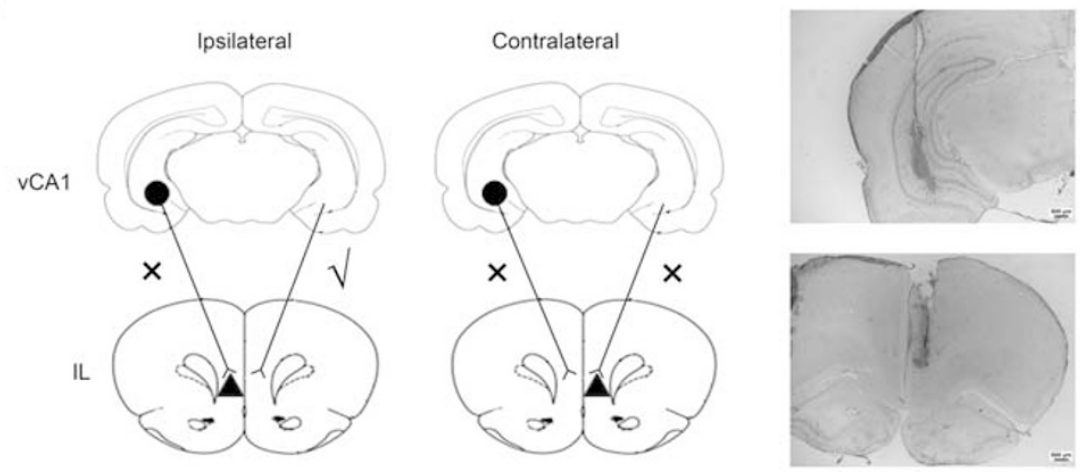

b

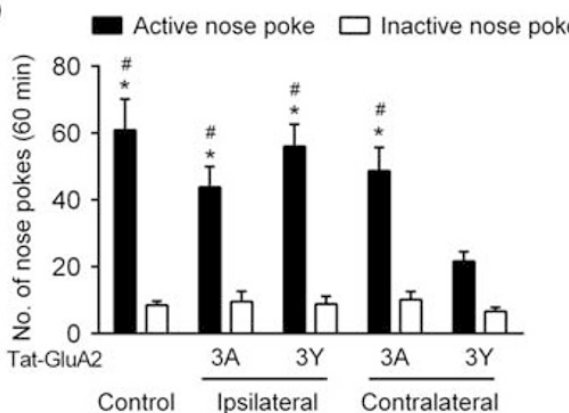

d

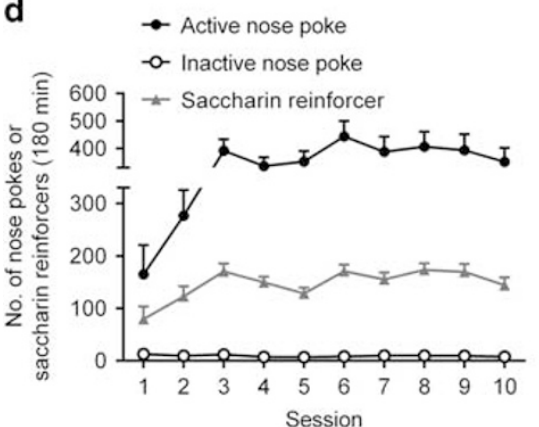

C

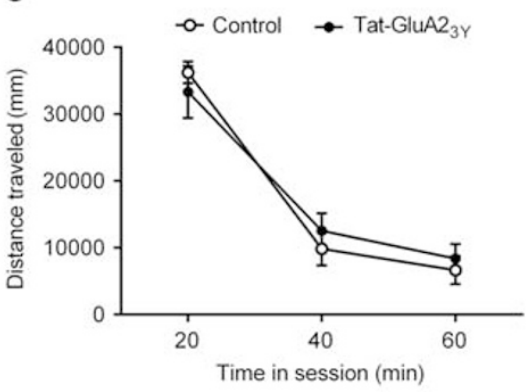

e

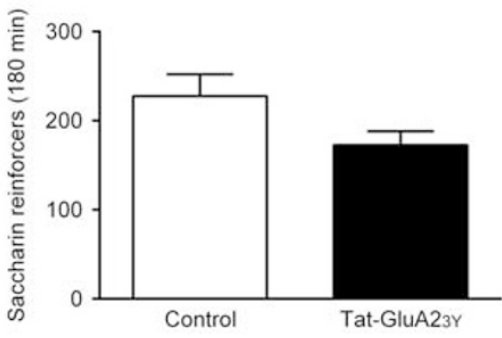

Figure 3 Pharmacological disconnection of the VCAI-IL pathway decreased context-induced reinstatement of heroin seeking. (a) Left, an overview of the disconnection procedure. Right, histological sites of cannula placements in the IL and vCAI. Scale bar, 500 um. (b) Number of nose-pokes during the contextinduced reinstatement tests after injections of $\mathrm{B}+\mathrm{M}$ in the $\mathrm{VCAI}$ and Tat-GluA2 $2_{3 \mathrm{~A}}$ or Tat-GluA2 $2_{3 Y}$ in the ipsilateral or contralateral side in the IL. Two-way ANOVA, ${ }^{*} P<0.05$ vs the number of inactive nose-poke of each group; ${ }^{\#} P<0.05$ vs the number of active nose-poke in the contralateral Tat-GluA2 $3 Y$ group, $n=6-9$ per group. $3 A$ and $3 Y$ stand for Tat-GluA2 $3 A$ and Tat-GluA2 $3 Y$, respectively. (c) Locomotor activity (distance traveled) during 20 min bins in the I- $h$ session after $\mathrm{B}+\mathrm{M}$ injection in the $\mathrm{VCA}$ I and Tat-GluA2 3 injection in the contralateral side in the IL, $n=7-9$ per group. (d) Saccharin $S A$ training, $n=I 4$ per group. (e) Number of saccharin reinforcers during the saccharin $S A$ test after $B+M / T a t-G l u A 2_{3 y}$ contralateral disconnection treatment, $n=7$ per group. Data are depicted as the mean \pm SEM.

phosphorylation at Y876 in the IL, which suggest enhanced GluA2 internalization after reinstatement testing.

\section{Experiment 3: Re-exposing rats to a Heroin-paired Context Impaired Basal Synaptic Transmission and Facilitated LTD Induction in the vCA1-IL Pathway}

To test the functional implication of suppressed synaptosomal GluA2 expression in IL, we examined basal synaptic transmission in the vCA1-IL pathway after the reinstatement testing. Input/output curves $(\mathrm{I} / \mathrm{O})$ were generated by collecting responses to a series of increasing stimulation intensities. The slope of I/O in the ABA group was lower than that in the $\mathrm{ABB}$ group (Figure $2 \mathrm{c}$ ), indicating that reexposure to the heroin-paired context suppressed basal synaptic transmission in vCA1-IL pathway. The statistical analysis showed a significant interaction between group and current intensities $\left(\mathrm{F}_{(4,24)}=3.90, P=0.0141\right)$. To further investigate the long-term synaptic plasticity changes induced by the reinstatement tests, we assessed the induction of LTD in the vCA1-IL pathway. Low-frequency burst stimulation (LFBS) was delivered in vCA1, and FPs were recorded in IL. The amplitudes of FPs were then normalized as percentage of the baseline for each rat. Results showed that the reduction of FPs amplitude was significantly higher in the ABA group $(41.1 \% \pm 5.0 \%)$ than in the $\mathrm{ABB}$ group $(14.0 \% \pm 5.9 \%$; $\mathrm{t}_{6}=3.51, P=0.0127$ ) (Figure $2 \mathrm{~d}$ and $\mathrm{e}$ ), indicating that reexposure to the heroin-paired context facilitated LTD induction in VCA1-IL pathway. 
Experiment 4: Pharmacological Disconnection of the vCA1-IL Pathway Decreased Context-induced Reinstatement of Heroin Seeking

We found that re-exposure to the heroin-paired context selectively depressed long-term vCA1-IL glutamatergic transmission. However, it is unknown whether this depression was required for context-induced reinstatement of heroin seeking. Thus, we employed a modified disconnection method: presynaptic unilateral $\mathrm{B}+\mathrm{M}$ inactivation of $\mathrm{vCA} 1$ with selective rescue of postsynaptic GluA2 depression (Tat$\mathrm{GluA}_{3 \mathrm{Y}}$, a synthetic peptide, can block the internalization of GluA2 (Brebner et al, 2005)) in contralateral IL. The results showed rats that received unilateral inactivation of vCA1 combined with ipsilateral IL rescue (Tat-GluA2 ${ }_{3 Y}$ )/no rescue
(Tat-GluA2 $2_{3 \mathrm{~A}}$ ) of GluA2 performed similarly to control rats in reinstatement testing (Figure $3 \mathrm{~b}$ ), suggesting that the integrity of vCA1-IL in one hemisphere was sufficient to control context-induced relapse to heroin seeking. Furthermore, rats that received unilateral vCA1 inactivation plus contralateral IL rescue of GluA2 (B+M/ Tat-GluA2 $3 \mathrm{Y})$ had significantly less number of active nose-pokes than control and no rescue (B $+\mathrm{M} /$ Tat-GluA2 $2_{3 \mathrm{~A}}$ ) groups (Figure $3 \mathrm{~b}$ ). The statistical analysis showed a significant interaction between the group and number of nose-poke $\left(\mathrm{F}_{(4,64)}=4.967, P=0.0015\right)$. The number of inactive nose-pokes was unaffected (Figure $3 b$ ). In order to rule out the possibility of motor impairment, we determined the effect of the pharmacological disconnection of the vCA1-IL pathway on locomotor activity in control

a

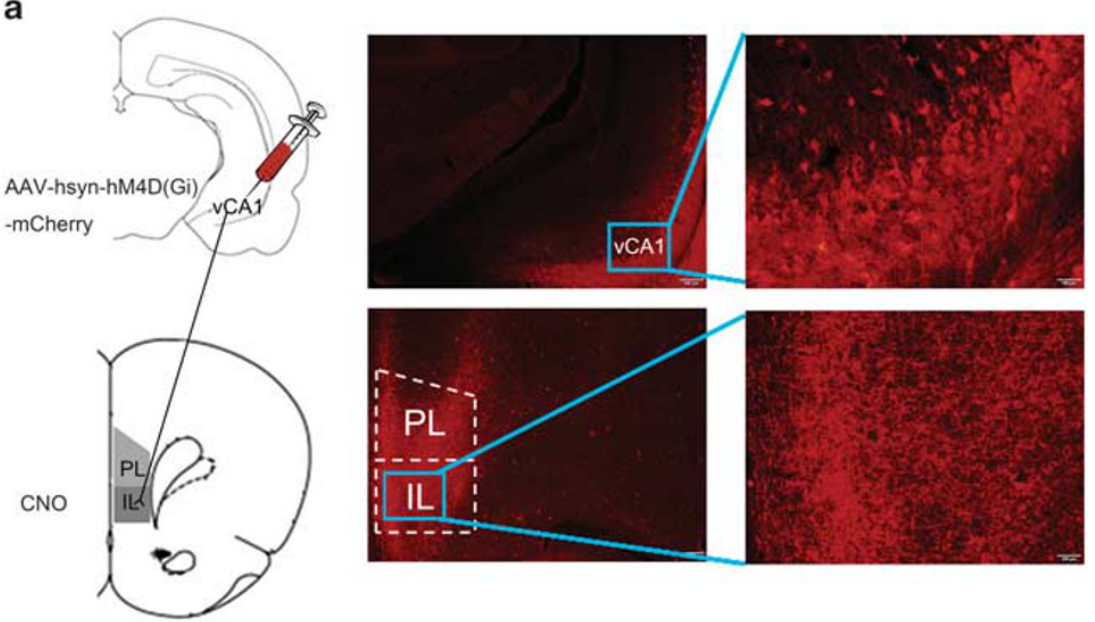

b

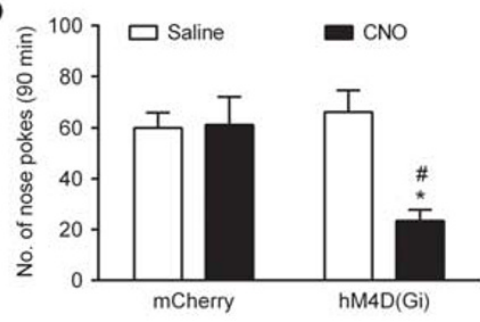

d

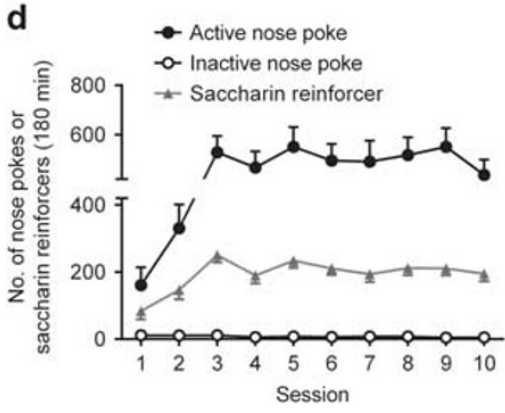

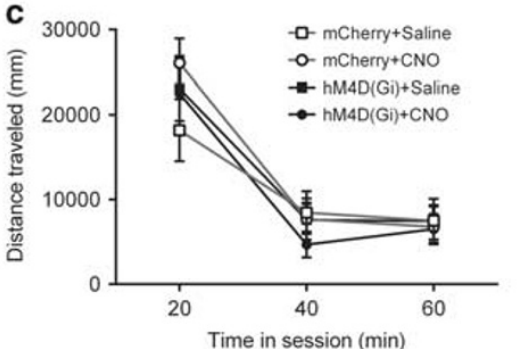

e

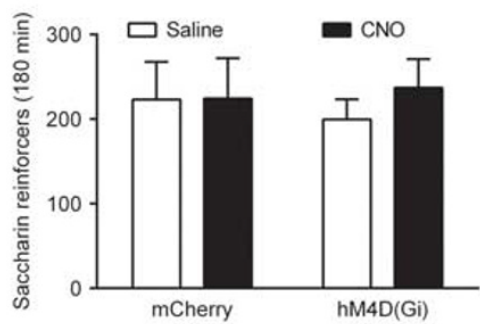

Figure 4 Chemogenetic silencing of the VCAI-IL pathway decreased context-induced reinstatement of heroin seeking. (a) Left, an overview of AAV injection sites in the VCAI and the IL. Right, representative expression of AAV8-hSyn-hM4D (Gi)-mCherry in cell bodies of the vCAI (top) and axon terminals in both the PL and IL (bottom) 6 weeks after AAV injected in bilateral VCAI. Scale bar (left) $500 \mu \mathrm{m}$ and (right) I00 $\mu \mathrm{m}$. (b) Number of active nose-pokes in rats with $\mathrm{hM4D}(\mathrm{Gi})$ or mCherry virus expression during the reinstatement testing after bilateral saline or CNO treatment in the IL. Two-way ANOVA, *P $<0.05$ vs the mCherry+CNO group; ${ }^{\#} P<0.05$ vs the $h M 4 D(G i)+$ Saline group, $n=7$ per group. (c) Locomotor activity (distance traveled) during 20 min bins in the I- $h$ session after bilateral saline or CNO treatment in the IL. (d) Saccharin SA training, $n=14$. (e) Number of saccharin reinforcers during the saccharin SA test after bilateral saline or $\mathrm{CNO}$ treatment in the $\mathrm{IL}, n=7$ per group. Data are depicted as mean $\pm \mathrm{SEM}$. 
and $\mathrm{B}+\mathrm{M} / \mathrm{Tat}-\mathrm{GluA} 2_{3 \mathrm{Y}}$ groups. No impairment in locomotion was found $\left(t_{14}=0.182, P=0.858\right.$; Figure $\left.3 c\right)$. To evaluate the role of vCA1-IL pathway in learning a natural reward behavior, we tested in rats for saccharin SA. During the training phase, the rats showed stable intake of saccharin reinforcers (Figure 3d). Disconnecting the vCA1-IL pathway had no effect on saccharin $\mathrm{SA} \quad\left(\mathrm{t}_{12}=1.893, P=0.083\right.$; Figure 3e). Together, our data indicate that the vCA1-IL glutamatergic depression is necessary for context-induced reinstatement of heroin seeking. a
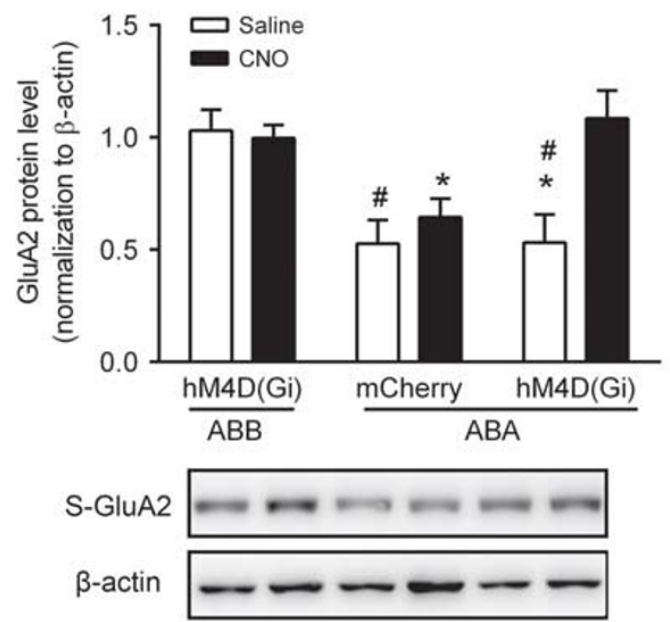

b

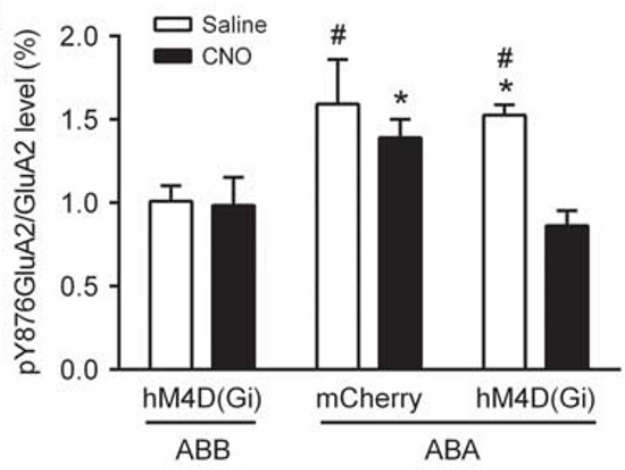

C

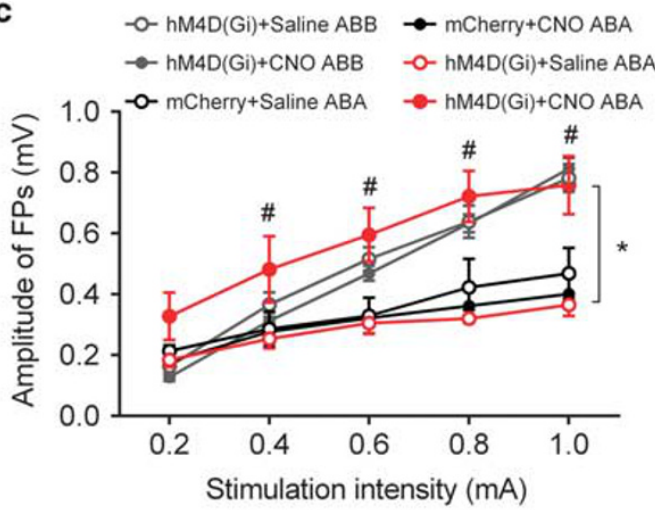

d

$\mathrm{hM} 4 \mathrm{D}(\mathrm{Gi}) \mathrm{hM} 4 \mathrm{D}(\mathrm{Gi})$ mCherry mCherry hM4D(Gi) hM4D(Gi)

+ Saline + $\mathrm{CNO}+$ Saline + $\mathrm{CNO}$ + Saline + CNO

ABB ${ }^{A B B}{ }^{A B A}{ }^{A B A}{ }^{A B A}$ the

o hM4D(Gi)+Saline ABB - mCherry+CNO ABA
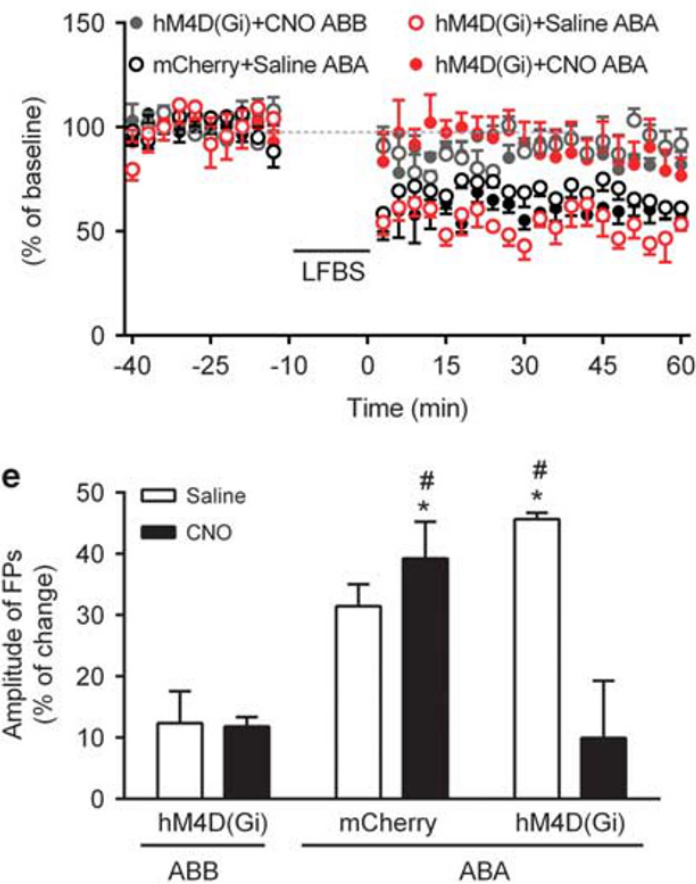

Figure 5 Chemogenetic inactivation of the vCAI-IL pathway reversed the changes of synaptosomal GluA2, pY876 GluA2 in the IL, basal synaptic transmission, and LTD induction in VCAI-IL pathway. (a) Synaptosomal protein level of GluA2 after bilateral saline or CNO injections after context-induced reinstatement of heroin seeking. Two-way ANOVA, ${ }^{*} P<0.05$ vs the $h M 4 D(G i)+C N O$ of $A B B$ group; ${ }^{\#} P<0.05$ vs the $h M 4 D(G i)+S a l i n e ~ o f ~ A B B$ group, $n=6-8$ per group. (b) Ratio of pY876 GluA2/GluA2 protein levels in the IL after bilateral saline or CNO treatment after context-induced reinstatement of heroin seeking. Two-way ANOVA, *P $<0.05$ vs the $h M 4 D(G i)+C N O$ of ABB group; ${ }^{\#} P<0.05$ vs the $h M 4 D(G i)+$ Saline of $A B B$ group, $n=6-8$ per group. (c) Input-output curves, ${ }^{*} P<0.05$ vs the $h M 4 D(G i)+$ Saline of $A B A$ group; ${ }^{\#} P<0.05$ vs each stimulation intensity of $h M 4 D(G i)+S a l i n e ~ o f ~ A B A$ group, $n=4-5$ per group. (d) LTD induction in the VCAI-IL pathway after LFBS stimulation, $n=4-5$ per group. Representative traces at the baseline and after LFBS stimulation are shown. Calibration: vertical scale bar, $0.25 \mathrm{mV}$; horizontal scale bar, $40 \mathrm{~ms}$. (e) Summary of the magnitude change of LFBS-induced LTD in each group. FP amplitude after the LFBS stimulation represented as a percent change from the baseline. Two-way ANOVA, *P $<0.05$ vs the hM4D(Gi)+CNO of ABB group; ${ }^{\#} P<0.05$ vs the $h M 4 D(G i)+$ Saline of ABB group, $n=4-5$ per group. Data are depicted as the mean \pm SEM. 
Experiment 5: Rescue of GluA2 Downregulation and LTD Facilitation by Chemogenetic Inactivation of the vCA1-IL Pathway Suppressed Context-induced Reinstatement of Heroin Seeking

To selectively inactivate the vCA1 projected neurons in IL during the reinstatement test, a Designer Receptor Exclusively Activated by Designer Drugs (DREADD)-based strategy was used. AAV-mCherry-infected vCA1 neurons were labeled red (Figure 4a, top) and vCA1 projection neuron terminals were readily visible in the IL (Figure 4a, bottom). Bilateral pretreatment of $\mathrm{CNO}$ (an exogenously administered ligand of DREADD) but not saline in the IL rescued synaptosomal GluA2 downregulation $\left(\mathrm{F}_{(2,34)}=4.83\right.$, $P=0.0142$; Figure 5a) and suppressed pY876 GluA2 increase $\left(\mathrm{F}_{(2,34)}=6.012, P=0.0058\right.$; Figure $\left.5 \mathrm{~b}\right)$ in the ABA group. No changes were observed in the ABB group (Figures $5 a$ and $b$ ). Bilateral $\mathrm{CNO}$ but not saline pretreatment also increased the slope of $\mathrm{I} / \mathrm{O}$ in $\mathrm{ABA} / \mathrm{hM} 4 \mathrm{D}(\mathrm{Gi})$ (Figure $5 \mathrm{c}$ ), indicating successful chemogenetic rescue of the decreased basal synaptic transmission in vCA1-IL pathway induced by reexposure to the heroin-paired context. The statistical analysis showed a significant interaction between group and current intensities $\left(\mathrm{F}_{(20,76)}=8.824, P<0.0001\right.$; Figure $\left.5 \mathrm{c}\right)$. Moreover, though the induction was successful in $\mathrm{ABA} / \mathrm{hM} 4 \mathrm{D}(\mathrm{Gi})$ group with bilateral saline pretreatment, LFBS failed to induce vCA1-IL LTD in the ABA/hM4D(Gi) group with bilateral CNO pretreatment. The statistical analysis showed a significant interaction between group and drug pretreatment $\left(\mathrm{F}_{(2,19)}=10.08, P=0.001\right.$; Figure $5 \mathrm{~d}$ and $\left.\mathrm{e}\right)$.

Based on the observation that chemogenetic inactivation rescued the molecular and synaptic suppression induced by re-exposure to heroin-paired context, we tested whether this chemogenetic inactivation was sufficient to decrease contextinduced reinstatement of heroin seeking. During the reinstatement tests, bilateral pretreatment of $\mathrm{CNO}$ in the IL significantly decreased the number of active nose-pokes in the $\mathrm{hM} 4 \mathrm{D}(\mathrm{Gi})$ group but not the mCherry group. The statistical analysis showed a significant interaction between drug pretreatment and the virus $\left(\mathrm{F}_{(1,24)}=7.772, P=0.0102\right)$. Inactivation of the vCA1-PL pathway had no effect on the active or inactive nose-poke responses (Supplementary Figure S3). Moreover, CNO pretreatment did not alter saccharin response (no effect of drug pretreatment, $\mathrm{F}_{(1}$, 26) $=0.390, P=0.538$; the virus, $\mathrm{F}_{(1,26)}=0.008, P=0.929$, interaction between drug pretreatment and the virus, $\mathrm{F}_{(1}$, 26) $=0.162, P=0.691$ ) or locomotor activity (main effect of time, $\mathrm{F}_{(2,66)}=46.22, P<0.0001$; no main effect of the group, $\mathrm{F}_{(3,26)}=0.545, P=0.654$, no time $\times$ the group interaction, $\mathrm{F}_{(6}$, 66) $=0.590, P=0.590)$ (Figure $4 \mathrm{c}-\mathrm{e}$ ).

Together, our results demonstrate that heroin-paired context re-exposure induces a downregulation of synaptosomal GluA2, an upregulation of pY876 GluA2 in the IL, inhibition of basal synaptic transmission, and facilitation of LFBS-induced LTD in the vCA1-IL pathway. Rescue of these molecular and synaptic depressions either by pharmacological or chemogenetic approach significantly decreases context-induced reinstatement of heroin seeking.

\section{DISCUSSION}

In the current study, we provide new evidence that the vCA1-IL projections play an important role in contextinduced reinstatement of heroin seeking in rats. First, we showed that the vCA1-IL, but not the vCA1-PL, glutamatergic projections are activated by re-exposing rats to a heroin-paired context. This effect was associated with the obstruction of basal synaptic transmission and the facilitation of LFBS-induced LTD in the vCA1-IL pathway. Second, we showed that the downregulation of synaptosomal GluA2 is associated with synaptic plasticity accompanied by pY876 GluA2 elevation. Further investigation showed that pharmacological inactivation of the vCA1-IL pathway inhibits context-induced reinstatement of heroin seeking without affecting operant responding for natural reward or locomotor activity. Chemogenetic silencing of the vCA1-IL pathway also reversed the synaptic plasticity and molecular alterations induced by context-induced reinstatement.

\section{The PL and IL Modulate Drug-Seeking Behavior}

The PL and IL are hypothesized to play opposing roles in drug-seeking behavior (promoting and suppressing, respectively) (Di Pietro et al, 2006; Peters et al, 2008). However, recent studies indicate that the roles of the PL and IL in reward processing are more complex than a simple PLpromoting $v s$ IL-extinguishing dichotomy. Previous studies showed that optogenetic inactivation of the PL decreases cocaine-induced reinstatement, but increases cocaine SA in rats, suggesting an inhibitory role of the PL on cocaine SA (Martin-Garcia et al, 2014). Furthermore, inactivation of IL or IL-NAc shell decreases context-induced reinstatement of heroin seeking (Bossert et al, 2011; Bossert et al, 2012). The complex roles of the PL and the IL in drug-seeking behavior may be due to several factors, including the type of drug, the context related to behavior, and the duration of drug taking. Moreover, the PL and the IL are different (Vertes, 2004) in reference to their projection to other reward-related brain regions. For example, the PL projects predominantly to the nucleus accumbens (NAc) core, whereas the IL projects mainly to the NAc shell (Berendse et al, 1992; Vertes, 2004). Additionally, the PL neurons project primarily to the capsular central amygdala and the basolateral amygdala (Beckstead, 1979; Vertes, 2004), whereas the IL projects to the medial, basomedial, and cortical amygdaloid, and the central amygdaloid nuclei (Hurley et al, 1991). Owing to the different connection patterns of the PL and the IL, they are likely to be involved in distinct neural circuits that mediate drug-seeking behavior.

In the present study, we focused on the different projections from the vCA1 to the PL and IL to determine their contributions to context-induced reinstatement of heroin seeking. The retrograde tracing results showed that the vCA1 projected to both the PL and IL, which is consistent with previous findings (Jay et al, 1996). More important, we also found that the vCA1 projections more heavily to the IL than to the PL. Re-exposure to a heroinpaired context selectively activated the vCA1-IL but not the vCA1-PL pathway. Additionally, inhibition of the vCA1-IL but not the vCA1-PL pathway using a DREADD-based approach decreased context-induced reinstatement of heroin 
seeking. Our results demonstrate the contribution of the vCA1-IL pathway to context-induced reinstatement of heroin seeking and highlight the different roles of IL and $\mathrm{PL}$ and their afferent projection in relapse to drug seeking.

\section{GluA2 Contributes to Drug-Seeking Behavior}

Relapse of drug-seeking behavior often occurs after the retrieval of drug-associated memories ( $\mathrm{Lv}$ et al, 2015; Torregrossa et al, 2011). The process involved in the retrieval and subsequent reconsolidation of the drug memories involves AMPARs trafficking and functional synaptic plasticity (Van den Oever et al, 2008). In the studies on retrieval of contextual fear memory, it has been reported that GluA2 undergoes endocytosis, a process associated with a decrease in AMPAR miniature excitatory postsynaptic currents (Rao-Ruiz et al, 2011) and an enhancement of LTD (Bhattacharya et al, 2016). In a study on cue-induced reinstatement of heroin seeking, it has been reported that this reinstatement causes GluA2 endocytosis and a decrease in AMPA/NMDA current ratios in the MPFC (Van den Oever et al, 2008). Consistent with previous studies showing that the decrease of GluA2 was associated with LTD expression, we found a decrease in synaptosomal GluA2 expression in the IL and a facilitation in LTD in the vCA1-IL pathway after context-induced reinstatement of heroin seeking.

Phosphorylation of GluA2 is regarded as primarily a posttranslational regulatory modification (Shepherd and Huganir, 2007). Phosphorylation of GluA2 at S880 (Seidenman et al, 2003) and Y876 (Hayashi and Huganir, 2004) promote the internalization of GluA2. We found that context-induced reinstatement of heroin seeking was associated with decreased synaptosomal GluA2 protein levels; this effect was associated with an increase in pY876 but not pS880 GluA2. There is evidence suggesting that the phosphorylation of pY876 GluA2 causes destabilization of GluA2 at the synaptosome, leading to receptor internalization (Hayashi and Huganir, 2004). This cellular process can be prevented byTat-GluA2 $2_{3 \mathrm{Y}}$ which mimics a tyrosineenriched region of the GluA2-C terminus (including Y869, Y873, and Y876) to block the phosphorylation of the GluA2 C-terminus and inhibit the internalization of GluA2 (Ahmadian et al, 2004; Scholz et al, 2010). We found that injection of Tat-GluA $2_{3 Y}$ into the IL decreased contextinduced reinstatement of heroin seeking, suggesting that GluA2 internalization plays an important role in this reinstatement.

\section{Multiple Neural Pathways Contribute to Context- induced Reinstatement of Heroin Seeking}

Previous studies have identified several neural pathways that mediate context-induced reinstatement of heroin seeking. Specifically, previous study showed that pharmacological inhibition of the glutamatergic projections from the ventromedial PFC to the NAc shell decreases context-induced reinstatement of heroin seeking (Bossert et al, 2012). Using a similar inactivation method, these investigators further found that the ventral subiculum of the hippocampus (vSub)-NAc shell, but not the vSub-vmPFC pathway is involved in this reinstatement (Bossert et al, 2016), an effect that seems inconsistent with our results. One possible explanation is that the projections investigated in the two studies were different. The vSub is the adjacent area of the vCA1, and from an anatomical perspective the vmPFC consists of the ventral PL, IL, and dorsal peduncular cortex (Riga et al, 2014). Another explanation is that different inactivation procedures were used in our study and Bossert et al's (2016) study. First, we performed a disconnection with vCA1 with $\mathrm{B}+\mathrm{M}$ in one hemisphere Tat-GluA2 $3 \mathrm{Y}$ (which selectively prevents AMPARs endocytosis) in IL in the contralateral hemisphere. In addition, we performed a DREADD-based strategy to selectively inhibit the vCA1-IL pathway, which directly inactivated the vCA1 terminals in the IL, but not of other inputs to the IL. Such a selective inactivation procedure may produce different behavioral effects compared to generalized inactivation. In support, a recent study has demonstrated that selective, but not generalized, silencing of IL neurons activated by alcohol cues disinhibits alcohol seeking (Pfarr et al, 2015). Recently, we found that the EC-dDG pathway plays a role in contextinduced reinstatement of heroin seeking by activating postsynapticGluN2B-ERK1/2 signaling in the dDG (Ge et al, 2017). These results and those described above indicate that multiple neural pathways contribute to context-induced reinstatement of heroin seeking. A question for future research is whether the vCA1-IL and EC-dDG, and other pathways (Marchant et al, 2015) interact with each other and ultimately control context-induced relapse to heroin seeking.

\section{FUNDING AND DISCLOSURE}

This work was supported by grants from the National Natural Science Foundation (grant number 31271163), the National Basic Research Program (grant number 2015CB553500) and the Science Fund for Creative Research Groups from the National Natural Science Foundation (81521063) of China to CL Cui. The remaining authors declare no conflict of interest.

\section{AUTHOR CONTRIBUTIONS}

Cailian Cui, Na Wang, and Feifei Ge conceived and designed the research; $\mathrm{Na}$ Wang and Feifei Ge performed the experiments and analyzed the data; Yijing Li, Xiaowei Sun, Xinjuan Wang, Shuli Liu, Haolin Zhang, Yan Liu, Meng Jia, and Mingda Yang provided technical support; Na Wang drafted the manuscript; and Cailian Cui, Feifei Ge, Linlin Sun, and $\mathrm{Na}$ Wang edited and revised the manuscript.

\section{REFERENCES}

Ahmadian G, Ju W, Liu L, Wyszynski M, Lee SH, Dunah AW et al (2004). Tyrosine phosphorylation of GluR2 is required for insulin-stimulated AMPA receptor endocytosis and LTD. EMBO J 23: $1040-1050$.

Beckstead RM (1979). An autoradiographic examination of corticocortical and subcortical projections of the mediodorsalprojection (prefrontal) cortex in the rat. J Comp Neurol 184: 43-62.

Beltrao P, Bork P, Krogan NJ, van Noort V (2013). Evolution and functional cross-talk of protein post-translational modifications. Mol Syst Biol 9: 714. 
Berendse HW, Galis-de Graaf Y, Groenewegen HJ (1992). Topographical organization and relationship with ventral striatal compartments of prefrontal corticostriatal projections in the rat. J Comp Neurol 316: 314-347.

Bhattacharya S, Kimble W, Buabeid M, Bhattacharya D, Bloemer J, Alhowail A et al (2016). Altered AMPA receptor expression plays an important role in inducing bidirectional synaptic plasticity during contextual fear memory reconsolidation. Neurobiol Learn Mem 139: 98-108.

Bossert JM, Adhikary S St, Laurent R, Marchant NJ, Wang HL, Morales $M$ et al (2016). Role of projections from ventral subiculum to nucleus accumbens shell in context-induced reinstatement of heroin seeking in rats. Psychopharmacology (Berl) 233: 1991-2004.

Bossert JM, Gray SM, Lu L, Shaham Y (2006). Activation of group II metabotropic glutamate receptors in the nucleus accumbens shell attenuates context-induced relapse to heroin seeking. Neuropsychopharmacology 31: 2197-2209.

Bossert JM, Liu SY, Lu L, Shaham Y (2004). A role of ventral tegmental area glutamate in contextual cue-induced relapse to heroin seeking. J Neurosci 24: 10726-10730.

Bossert JM, Poles GC, Wihbey KA, Koya E, Shaham Y (2007). Differential effects of blockade of dopamine D1-family receptors in nucleus accumbens core or shell on reinstatement of heroin seeking induced by contextual and discrete cues. J Neurosci 27: 12655-12663.

Bossert JM, Stern AL (2014). Role of ventral subiculum in contextinduced reinstatement of heroin seeking in rats. Addict Biol 19: 338-342.

Bossert JM, Stern AL, Theberge FR, Cifani C, Koya E, Hope BT et al (2011). Ventral medial prefrontal cortex neuronal ensembles mediate context-induced relapse to heroin. Nat Neurosci 14: 420-422.

Bossert JM, Stern AL, Theberge FR, Marchant NJ, Wang HL, Morales $M$ et al (2012). Role of projections from ventral medial prefrontal cortex to nucleus accumbens shell in context-induced reinstatement of heroin seeking. J Neurosci 32: 4982-4991.

Bouton ME (1993). Context, time, and memory retrieval in the interference paradigms of Pavlovian learning. Psychol Bull 114: 80-99.

Brebner K, Wong TP, Liu L, Liu Y, Campsall P, Gray S et al (2005). Nucleus accumbens long-term depression and the expression of behavioral sensitization. Science 310: 1340-1343.

Choi FY, Ahn S, Wang YT, Phillips AG (2014). Interference with AMPA receptor endocytosis: effects on behavioural and neurochemical correlates of amphetamine sensitization in male rats. J Psychiatry Neurosci 39: 189-199.

Conklin CA, Tiffany ST (2002). Applying extinction research and theory to cue-exposure addiction treatments. Addiction 97: 155-167.

Connor SA, Wang YT (2016). A place at the table: LTD as a mediator of memory genesis. Neuroscientist 22: 359-371.

Crombag HS, Bossert JM, Koya E, Shaham Y (2008). Review. Context-induced relapse to drug seeking: a review. Philos Trans $R$ Soc Lond B Biol Sci 363: 3233-3243.

Dalton GL, Wang YT, Floresco SB, Phillips AG (2008). Disruption of AMPA receptor endocytosis impairs the extinction, but not acquisition of learned fear. Neuropsychopharmacology 33: 2416-2426.

Di Pietro NC, Black YD, Kantak KM (2006). Context-dependent prefrontal cortex regulation of cocaine self-administration and reinstatement behaviors in rats. Eur $J$ Neurosci 24: 3285-3298.

Dias C, Wang YT, Phillips AG (2012). Facilitated extinction of morphine conditioned place preference with Tat-GluA2(3Y) interference peptide. Behav Brain Res 233: 389-397.

Fanselow MS, Dong HW (2010). Are the dorsal and ventral hippocampus functionally distinct structures? Neuron 65: 7-19.
Ge F, Wang N, Cui C, Li Y, Liu Y, Ma Y et al (2017). Glutamatergic projections from the entorhinal cortex to dorsal dentate gyrus mediate context-induced reinstatement of heroin seeking. Neuropsychopharmacology 42: 1860-1870.

Hayashi T, Huganir RL (2004). Tyrosine phosphorylation and regulation of the AMPA receptor by SRC family tyrosine kinases. J Neurosci 24: 6152-6160.

Hurley KM, Herbert H, Moga MM, Saper CB (1991). Efferent projections of the infralimbic cortex of the rat. J Comp Neurol 308: 249-276.

Hyman SE, Malenka RC (2001). Addiction and the brain: the neurobiology of compulsion and its persistence. Nat Rev Neurosci 2: 695-703.

Jay TM, Burette F, Laroche S (1996). Plasticity of the hippocampalprefrontal cortex synapses. J Physiol Paris 90: 361-366.

Kadriu B, Guidotti A, Chen Y, Grayson DR (2012). DNA methyltransferases1 (DNMT1) and 3a (DNMT3a) colocalize with GAD67-positive neurons in the GAD67-GFP mouse brain. J Comp Neurol 520: 1951-1964.

Khoo SY, Gibson GD, Prasad AA, McNally GP (2017). How contexts promote and prevent relapse to drug seeking. Genes Brain Behav 16: 185-204.

Lasseter HC, Xie X, Ramirez DR, Fuchs RA (2010). Sub-region specific contribution of the ventral hippocampus to drug contextinduced reinstatement of cocaine-seeking behavior in rats. Neuroscience 171: 830-839.

Liu QR, Rubio FJ, Bossert JM, Marchant NJ, Fanous S, Hou X et al (2014). Detection of molecular alterations in methamphetamineactivated Fos-expressing neurons from a single rat dorsal striatum using fluorescence-activated cell sorting (FACS). J Neurochem 128: $173-185$.

Lv XF, Sun LL, Cui CL, Han JS (2015). NAc shell Arc/Arg3.1 protein mediates reconsolidation of morphine CPP by increased GluR1 cell surface expression: activation of ERK-coupled CREB is required. Int J Neuropsychopharmacol 18: 1-10.

Mahler SV, Vazey EM, Beckley JT, Keistler CR, McGlinchey EM, Kaufling J et al (2014). Designer receptors show role for ventral pallidum input to ventral tegmental area in cocaine seeking. Nat Neurosci 17: 577-585.

Mao SC, Chang CH, Wu CC, Orejarena MJ, Manzoni OJ, Gean PW (2013). Inhibition of spontaneous recovery of fear by mGluR5 after prolonged extinction training. PLoS One 8: e59580.

Marchant NJ, Kaganovsky K, Shaham Y, Bossert JM (2015). Role of corticostriatal circuits in context-induced reinstatement of drug seeking. Brain Res 1628(Pt A): 219-232.

Martin-Garcia E, Courtin J, Renault P, Fiancette JF, Wurtz H, Simonnet A et al (2014). Frequency of cocaine self-administration influences drug seeking in the rat: optogenetic evidence for a role of the prelimbic cortex. Neuropsychopharmacology 39: 2317-2330.

Myers B, Mark Dolgas C, Kasckow J, Cullinan WE, Herman JP (2014). Central stress-integrative circuits: forebrain glutamatergic and GABAergic projections to the dorsomedial hypothalamus, medial preoptic area, and bed nucleus of the stria terminalis. Brain Struct Funct 219: 1287-1303.

O'Brien CP, Childress AR, McLellan AT, Ehrman R (1992). Classical conditioning in drug-dependent humans. Ann NY Acad Sci 654: 400-415.

Peters J, LaLumiere RT, Kalivas PW (2008). Infralimbic prefrontal cortex is responsible for inhibiting cocaine seeking in extinguished rats. J Neurosci 28: 6046-6053.

Pfarr S, Meinhardt MW, Klee ML, Hansson AC, Vengeliene V, Schonig K et al (2015). Losing control: excessive alcohol seeking after selective inactivation of cue-responsive neurons in the infralimbic cortex. J Neurosci 35: 10750-10761.

Rao-Ruiz P, Rotaru DC, van der Loo RJ, Mansvelder HD, Stiedl O, Smit AB et al (2011). Retrieval-specific endocytosis of GluA2AMPARs underlies adaptive reconsolidation of contextual fear. Nat Neurosci 14: 1302-1308. 
Riga D, Matos MR, Glas A, Smit AB, Spijker S, Van den Oever MC (2014). Optogenetic dissection of medial prefrontal cortex circuitry. Front Syst Neurosci 8: 230.

Scholz R, Berberich S, Rathgeber L, Kolleker A, Kör G, Kornau HC (2010). AMPA receptor signaling through BRAG2 and Arf6 critical for long-term synaptic depression. Neuron 66: 768-780.

Shepherd JD, Huganir RL (2007). The cell biology of synaptic plasticity: AMPA receptor trafficking. Annu Rev Cell Dev Biol 23: 613-643.

St Onge JR, Floresco SB (2010). Prefrontal cortical contribution to risk-based decision making. Cereb Cortex 20: 1816-1828.

Takita M, Izaki Y, Jay TM, Kaneko H, Suzuki SS (1999). Induction of stable long-term depression in vivo in the hippocampalprefrontal cortex pathway. Eur J Neurosci 11: 4145-4148.

Torregrossa MM, Corlett PR, Taylor JR (2011). Aberrant learning and memory in addiction. Neurobiol Learn Mem 96: 609-623.

Van den Oever MC, Goriounova NA, Li KW, Van der Schors RC, Binnekade R, Schoffelmeer AN et al (2008). Prefrontal cortex AMPA receptor plasticity is crucial for cue-induced relapse to heroin-seeking. Nat Neurosci 11: 1053-1058.

Vertes RP (2004). Differential projections of the infralimbic and prelimbic cortex in the rat. Synapse 51: 32-58.
Wikler A (1973). Requirements for extinction of relapse-facilitating variables and for rehabilitation in a narcotic-antagonist treatment program. Adv Biochem Psychopharmacol 8: 399-414.

Yu YJ, Chang CH, Gean PW (2013). AMPA receptor endocytosis in the amygdala is involved in the disrupted reconsolidation of methamphetamine-associated contextual memory. Neurobiol Learn Mem 103: 72-81.

(c) (i) $\odot$ This work is licensed under a Creative Commons Attribution-NonCommercial-NoDerivs

International License. The images or other third party material in this article are included in the article's Creative Commons license, unless indicated otherwise in the credit line; if the material is not included under the Creative Commons license, users will need to obtain permission from the license holder to reproduce the material. To view a copy of this license, visit http://creativecommons.org/licenses/by-nc-nd/4.0/

(C) The Author(s) 2018

Supplementary Information accompanies the paper on the Neuropsychopharmacology website (http://www.nature.com/npp) 